\title{
Chapter 5 \\ On the Critical, Morally Driven, Self-reflective Agents of Change and Transformation: A Literature Review on Culturally Competent Leadership in Higher Education
}

\author{
Alessandra Pecci, Jack Frawley, and Tran Nguyen
}

\section{Introduction}

Cultural competence philosophy and praxis was born out of healthcare provision in the 1980s. As such, the essence of care cannot be separated from cultural competence practice. Study of the concept has since been extended into the areas of business, the social sciences, and education (Betancourt, Green, Carrillo, \& Park, 2005; Ranzijn \& Nolan, 2009; UA, 2011a, b). The provision of care in this last area, education, sets the tone and direction of our study. This is to remind educational organisations that they have a duty of care for and to their students, as well as their staff, and to succeed in doing so requires developing cultural competence dynamically and holistically at institutional, organisational and individual (personal and professional) levels.

This whole-of-institution approach includes, for example, "examining individual attitudes and practice in teaching as well as management, executive, policy and strategic commitment to revise and assess capacity to implement culturally competent teaching, learning, academic, research and employment spaces" (Taylor, Durey, Mulcock, Kickett, \& Jones, 2015, p. 37). Moses (2014) echoes this call for multilevelled leadership required for transformational change, particularly as it relates to diversity and inclusion policies and practices. She contends that:

If the goal of embracing diversity in our colleges and universities is transformational change, then it is an institutional imperative and responsibility. It is everyone's job. While sustained leadership from the top of the leadership chart is critical, it is not enough. The job of diversity and transformation of the academy takes sustained and intentional efforts at all levels of the institution. (Moses, 2014, p. 94)

\footnotetext{
A. Pecci $(\bowtie)$

Faculty of Society and Design, Bond University, Gold Coast, QLD, Australia e-mail: apecci@bond.edu.au

J. Frawley $\cdot$ T. Nguyen

National Centre for Cultural Competence, the University of Sydney, Sydney, NSW, Australia

(C) The Author(s) 2020

J. Frawley et al. (eds.), Cultural Competence and the Higher Education Sector, https://doi.org/10.1007/978-981-15-5362-2_5
} 
This literature review maps, examines and draws on existing scholarship that centres on the notion of culturally competent leadership, to situate its current application and prospective applicability to the higher education sector. Three fundamental research questions have guided this review: (a) what is meant by culturally competent leadership? (b) what does it look like in the higher education sector? and (c) is culturally competent leadership discourse, theory and practice reflected in the Australian experience and if so, how? This review therefore aims to chart theoretical concepts and discourse, as well as pedagogical trends and leadership initiatives in cultural competence in the higher education sector. Our findings reveal a corpus of pedagogical praxis, national and international, grounded in critical theory, which can guide and inform culturally competent leadership initiatives beyond and thereafter in higher education.

\section{Method}

This review is integrative in its approach, having sourced predominantly qualitative research findings and, to a lesser extent, quantitative research. The review draws primarily from the literature in Australia, New Zealand, Canada and the USA where cultural competence discourse, theory and practice are most prominent and prolific. The increased attention paid to cultural competence in those countries can be attributed to their shared histories as settler-colonial societies (Belich, 2009; Veracini, 2011). We pay attention to the salient notions in culturally competent leadership and its many interpretations and designations, in the higher education sector. The review covers peer-reviewed journals, books and book chapters, and non-peerreviewed articles. As culturally competent leadership is still an under-researched area, the review also examines the grey literature, including dissertations, government reports and frameworks, and conference papers. Literature was sourced electronically from various academic research databases, including the Australian Council for Educational Research (ACER), Google Scholar, AEI-ATSIS (Informit), Expanded Academic, ProQuest and Theses Global.

Mindful of the varying concepts often associated with cultural competence (Burchum, 2002), we anticipated the concept of culturally competent leadership would constrain our search and limit our results. A preliminary search validated our prediction, with less than half a dozen items resulting. The choice of search terms thus needed to be expanded to include the breadth of terms associated with cultural competence, including cultural capability, cultural responsiveness, cultural intelligence, and cultural proficiency. The review then expanded the search terms further to include the leadership denomination, hence culturally capable leadership, culturally responsive leadership, culturally intelligent leadership, strategic diversity leadership and culturally proficient leadership. Our refined search terms and subsequent review revealed an additional set of concepts, namely diversity leadership, transformative leadership, moral leadership, intercultural leadership and applied critical leadership, which have been included as part of this review. 
We begin by mapping and examining the range of designations used in scholarship, mainly from the USA, Canada and New Zealand that describe leadership in the cultural competence space in higher education. This responds to our first two research questions by providing an overview of prominent theory and discourse and bringing to light the binding thread of common attributes, behaviours, knowledge and skills seen to be fundamental to the practice of culturally competent leadership in educational settings. This review then moves to cultural competence in Australian higher education, providing the backdrop needed to address our third and final research question. We set the context by exploring the rationale for cultural change within Australian universities, and how the higher education sector has heeded the call for embedding cultural competence. The review then presents distinctly Australian voices representing scholarship and exemplary practice of cultural competence in local higher education contexts, which are presented as leadership initiatives in their own right, irrespective of whether these initiatives self-ascribe the term "leadership." We then briefly present points of tension and contention in Australian scholarship around cultural competence initiatives, in an attempt to bring to light the burgeoning nature of this field of research and practice in Australian higher education, and underscore the contributions of home-grown, Australian voices to the cultural competence and culturally competent leadership discourse. We conclude by contemplating opportunities for continued scholarly debate and practice, moving forward.

\section{Culturally Competent Leadership Discourse: A Cartography of Sorts}

We noted above that as a result of the varying conceptual associations of the term "cultural competence," it was anticipated that a proportionally equal variety would be reflected in associations with the term and concept of "culturally competent leadership." Following is a summary list of the wide range of designations for culturally competent leadership featuring in the scholarship consulted, which validates our point:

- sustainable, culturally competent leadership (Thompson, Forde \& Otieno, 2017)

- culturally proficient leadership (Terrell \& Lindsey, 2008)

- culturally responsive leadership (Beachum, 2011; Gooden, 2005, 2010; López, 2016; Santamaría \& Santamaría, 2016)

- diversity leadership (Aguirre \& Martinez, 2006; Chin \& Trimble, 2014; Chin, Desormeaux, \& Sawyer, 2016; Cooper, He, \& Levin, 2011; Eagly \& Chin, 2010; Moses, 2014)

- leadership for social justice (Dantley \& Green, 2015; Santamaría \& Santamaría, 2016; Terrell \& Lindsey, 2008)

- applied critical leadership (Santamaría \& Santamaría, 2016; Zavala \& Tran, 2016) 
- transformative leadership (Bennis, 1986; Burns, 1978; Davis, 2006; Grace, 2016; Marbley, Bonner II, Robinson, Stevens, Li, Phelan, \& Huang, 2015; Mezirow, 1991, 1996; Quantz, Rogers, \& Dantley, 1991; Shields, 2010; Taylor, 2006; Weiner, 2003)

- moral leadership (Bezzina \& Tuana, 2014)

- cosmopolitan perspectives on academic leadership (Su \& Wood, 2017)

- interculturalism and intercultural leadership (d'Arbon, Fasoli, Frawley \& Ober, 2009; Frawley, et al. 2010; Frawley \& Fasoli, 2012)

- strategic diversity leadership (Damon, 2013)

- pluralistic leadership (Kezar, 2000).

Our review of the literature reveals that, despite the diverse and varied nature of designations given to the notion of leading in a culturally competent way, leadership in this space implies an underlying set of attributes, skills and behaviours, as well as knowledge, that run across, and are foundational to, all terms encountered as part of our review. Chun and Evans (2016) observe from the US higher education context that the continued dominance of white, male, heterosexual perspectives has failed to foster a representative bureaucracy that is responsive to the need of diverse students. The body of scholarship consulted posits that leadership in this space equates to courage, advocacy for social justice and human rights, and a willingness and ability for reflexive practice and self-awareness. Culturally competent leaders work to identify, transform and eradicate systems that generate inequity, disparity and social injustice; for example, culturally competent leaders in higher education settings display characteristics of "civility, ethical behaviour, data-driven decision-making and cultural sensitivity" (Thompson et al., 2017, p. 79); and Dantley and Green (2015, p. 821) argue that "educational leadership must contend with and embrace the call to engage notions of social justice, academic achievement, accountability, community and cultural change."

Importantly, leadership in this space has an explicit moral dimension. To lead within a culturally competent framework requires leaders who develop a more explicit moral literacy (Bezzina \& Tuana, 2014) concerning situations in which their organisations engage in cultural change. This requires leaders who are capable of exploring their sense of moral purpose in their work through critical reflection, appreciating the importance of culture in leading ethically, and understanding the power of moral purpose as a mobiliser of practice. This ability and willingness to mobilise underpin the notions of agency in culturally competent leadership, and that "leadership is not based on a title; indeed, one can be a change agent without being the person with the label of leader" (Komives \& Wagner, 2016, p. 401). Adserias, Charleston, \& Jackson's (2017) review of literature on diversity leadership similarly concludes, and citing Birnbaum (1992, p. 151): "presidents are not the only source of leadership [in implementing diversity agendas]", neither can they shoulder the burden of cultural change, alone. Adserias et al. (2017) further underscore, and citing Kezar, Bertram Gallant, and Lester (2011, p. 147), there is a need for faculty and grassroots leadership initiatives to be strategically "aligned with academic culture and institutional methods" in that this allows for "grassroots leaders to operate under the radar". 
This review, therefore, positions culturally competent leadership in the values category of leadership theory, otherwise referred to as authentic leadership, which is "knowledge-based, values informed" and requires "professionally effective, ethically sound, and consciously reflective practices" in educational administration (Begley, 2001, p. 354). What has also been evident in reviewing the scholarship on culturally competent leadership in higher education is the salience of critical theory, of diversity and inclusion, and of equity and access discourse. Critical theory is defined as "a form of theorization motivated by a deep concern to overcome social injustice and the establishment of more just social conditions" (Kemmis, 2006, p. 125). Jurgen Habermas is credited with underscoring the importance of reflexivity and critical selfreflection in broader reflective critique practices and processes. A recurring message across the literature consulted is that educational leaders in this space need to commit to critical conversations around the historical, social and material legacies of colonial practices, if they wish to enact systemic change and transformation. Shultz and Viczko (2016, p. 2) note, for example, that even higher education institutions "have not escaped this [colonial] legacy, and the durability of issues and intersections of race, gender, and class violence are evident in our organisations." On the criticality of the systems that perpetuate longstanding injustices, López (2016, p. 20) asserts that "educational leaders who ground their work in critical perspectives seek to create social change by challenging the status quo and systems of power that dominate and subjugate."

On the subject of power, Kezar's $(2000,2008)$ work offers valuable insights into how conditions of power relate to interpretations of leadership. She sees power as a "positioning force" within higher education institutions (2000, p. 724) and draws on positionality theory to help contextualise differing perspectives on and experiences of leadership in the higher education context. Understandings of power are based on experience, in other words on one's position. She notes how "human agency is conceptualised as important to understanding power relations: power conditions do not simply shape people, people shape power conditions and the resultant relations (Kondo, 1990). Thus, power conditions are negotiated and socially constructed: they can be transformed. They are not a static force..." (2000, p. 727). She also explores the relationship of power conditions to the ways in which individuals construct and engage with leadership. Kezar's 2000 study concludes how power conditions are closely tied to the particular history of a campus and the individual background of individuals and asserts that positionality theory offers an insightful means to better understand leadership, and leadership potential in higher education contexts.

Kezar's later (2008) work highlighted the nature of politics in higher education institutions and explored the politics surrounding transformational change issues such as diversity. She notes how the corporatisation and commercialisation of universities have resulted in the creation of interest groups, in turn creating a more political and politicized environment on campus, whereby the wide range of interest groups compete for resources, for a voice, for space. She identifies politics (comprised of conflict, resistance and competing values-p. 411) as that which thwarts transformation and change efforts. Kezar ultimately draws on political theory as a framework for 
understanding how political strategies (such as mapping the political terrain, coalition building and developing advocates/allies, persuasion, bargaining/negotiation, mediation and persistence) can aid in overcoming barriers to transformation and change.

The importance of critical approaches to leadership in educational settings is also underscored by Beachum (2011), who provides a summary of the practices, skills and attributes of culturally responsive leadership as follows:

1. the development of emancipatory consciousness that focuses on educators' awareness of the history and detrimental impact of societal inequities,

2. equitable insights that focus on the development of attitudes that promote inclusion throughout the school community, and

3. engagement in reflexive practices whereby educators critically examine the work that they do.

Johnson and Fuller (2014, p. 1), similarly to Beachum (2011), contend that culturally responsive leaders place emphasis on "developing a critical consciousness among both students and faculty to challenge inequities in the larger society." Similarly, Mansfield and Jean-Marie (2015) argue that change and transformation require raising the "critical consciousness" of members of higher education institutions, in so far as "the change begins within us to choose to develop into transformational and critical leaders who can serve the needs of a diverse populace by serving as a voice for historically underserved communities" (Cruz, 2015, Epilogue).

The literature reviewed also identifies mindfulness, critical self-reflection and the importance of undertaking journeys of self-development as foundational practices, skills and attributes that enable culturally competent leadership. López (2016) notes that culturally responsive leadership demands "courage, taking risks, journeying, dealing with tensions, developing agency, and deep critical reflection" and that "critical leadership begins with examination of self" (p. 23). A sense of self, self-awareness and mindfulness are, as Tuleja (2014) notes, "often referred to as the reflective practice" (pp. 7-8). Day (2000, p. 123) similarly contends that successful educational leaders engage in a range of reflective practices and that effective leadership is "as much about developing the self as it is about capacity building in others and such effective leadership requires an intelligent head and an intelligent heart."

Terrell and Lindsey (2008, p. 4) support calls for "embracing leadership as a very personal journey of commitment and vision," with a focus on reflective practice. The authors contend that "culturally proficient leadership is distinguished from other leadership approaches in that it is anchored in the belief that a leader must clearly understand one's own assumptions, beliefs, and values about people and cultures different from one's self in order to be effective in cross-cultural settings" (2008, p. 4). Guerra and Pazey (2016) reaffirm the primacy of self-examination and assessment in the cultural competence journey, noting that:

If we have not examined our own assumptions, beliefs, biases about race, ethnicity, sexual orientation, gender, class, dis/ability, and other forms of diversity, how can we in turn effectively prepare aspiring leaders to lead for social justice? .... We must model the type of leadership within our own organizations that we expect our graduates to create. (p. 1752) 
Terrell and Lindsey (2008) identify specific attributes and skills of the culturally proficient leader, including a commitment to lifelong learning and critical selfreflection, and propose constructing cultural autobiographies as a way of generating a sense of self and self-awareness. hooks [sic] (2010) similarly argues that understanding our biographies along the lines of social class, ethnicity, gender and ability can help us to begin to name and expose the norms of cultural practice that we live, and which have shaped our dispositions. Cooper et al. (2011) also discuss the importance of constructing cultural autobiographies as a way of examining individual dispositions about, and experiences with, diversity. Meanwhile, Damon (2013) proposes what he terms as "the diversity idea framework", as this framework, he argues, would enable educational leaders to develop the type of cultural intelligence needed to become strategic diversity leaders.

Complementing the skills, attributes and behaviours required to lead for transformation and change, Horsford, Grosland, and Gunn (2011) further single out knowledge of political, social and historical contexts, as do Su and Wood (2017, p. 2), who refer to notions of historicity and situational specificity as central to understandings of leadership for cultural change and transformation in higher education. Knowledge of an institution's organisational culture is also seen to be critical for leadership and advocacy efforts in higher education. To this end, Komives and Wagner (2016) warn that change agents need to understand the context in which they are practising leadership, and gain knowledge about their organisation and where they and their group are situated within the organisation. Ottmann (2009, p. 5) similarly warns that it is "essential for leadership to have an in-depth understanding of organisational culture, as understanding at this level can provide leaders with ideas that would contribute to the success for a change initiative."

Critical scholars also call for an examination and understanding of the experiences of both students and staff who endure inequities and discrimination, based on any one dimension or combined dimensions of their identities (see, e.g., Chin \& Trimble, 2014; Chin et al., 2016; Cooper et al., 2011; Eagly \& Chin, 2010; Jones \& McEwen, 2000; Zavala \& Tran, 2016). Making language, gender and social class visible topics for discussion, as Terrell and Lindsey (2008) propose, begins to normalise both the act and intent in regard to uncovering disparities, discrimination and injustices, in a safe space. In a similar strain, Santamaría \& Santamaría (2016), and Santamaría (2014), draw on intersectionality discourse and strengths-based approaches to educational leadership in proposing the notion of applied critical leadership, which manifests in practice when:

an educational leader is able to analyse and think more deeply about their practice, asking questions such as, "in what ways does my identity enhance my ability to see, understand, or consider alternate perspectives in my leadership practice?" This conceptualization pushes educational leaders' thinking about leadership for social justice toward thinking about leadership practice or qualities that result in social justice and educational equity. (Santamaría, 2014, p. 357)

Santamaría \& Santamaría (2016) identify a number of common practices among applied critical leaders which include, but are not limited to, the following: 
- willingness to initiate and engage in critical conversations with individuals and groups even when the topic is not popular, for the greater good of the whole group,

- willingness to choose to assume a Critical Race Theory (CRT) or critical lens in order to consider multiple perspectives of critical issues,

- use of consensus-building as the preferred strategy for decision-making,

- have a moral imperative towards change and improving education for all, and

- being led by what they call "spirit," or practising a variation of servant leadership for those who work ultimately to serve the greater good.

Transformative leadership, which foregrounds critical theory in its discourse, focuses on systemic change and criticality towards the systems that misuse power and privilege to perpetuate disparity, inequity and injustice. As Halualani and Nakayama (2010) contend, the intercultural field is no longer limited to the notion of norms, values and behaviours; instead, culture should now be understood as a site of struggle and contestation. Accordingly, Weiner (2003) posits that transformative leaders must learn to work in dominant structures of power and authority to exercise effective oppositional power, resistance and activism, and moral courage to persist. Similarly, Marbley et al. (2015, p. 46) note, "Transformative leadership calls for an overhauling and revolutionising of human and social systems and the need to deconstruct and reconstruct privileged frameworks to ones that are more equitable and culturally grounded." Shields draws on Burns' (1978) seminal work on transactional and transformational leadership, in which he highlights the moral and ethical dimensions of leadership as intrinsic components of leadership and leading. Shields (2010) draws inspiration from Freire's $(1970,1998)$ work on transformative ideals in education and his calls for personal and dialogic relationships to support education-accordingly, in the absence of such relationships, education serves to "deform rather than to transform" (Shields, 2010, p. 566). Shields (2010, p. 559) also contends that transformative leadership theory can guide the practice of educational leaders who want to affect both educational and broader social change, in that it speaks to matters of justice and democracy, and critiques inequitable practices.

Similarly, and in their review of transformational leadership literature, Adserias et al. (2017, p. 319) underscore Aguirre and Martinez's (2002, 2006) and Tierney's (1989) assertion that transformational approaches to leadership "hold potential for both understanding and conceptualizing the transformative changes necessary to ameliorate systemic oppressions, such as those based on race, ethnicity, gender, and other identities that are socially marginalized". Adserias et al. (2017, p. 319) further highlight Aguirre and Martinez's (2002, 2006) claim that transformational leadership indeed has "greater potential for leading the type of large-scale, longterm organizational, and cultural changes" required by the diversity agenda in higher education contexts. Adserias et al.'s review (p. 319) further emphasises Bass and Riggio's (2006) work for its identification of four distinct tactics transformational leaders employ, namely: (a) idealized influence (lead by example); (b) inspirational motivation; (c) intellectual stimulation (inspire and support creative thinking and problem solving); and (d) individualized consideration (coaching and mentoring). 
Quantz et al. (1991) contend that transformative leadership "requires a language of critique and possibility" (Quantz et al., 1991, p. 105), and that a "transformative leader must introduce the mechanisms necessary for various groups to begin conversations around issues of emancipation and domination" (Quantz et al., 1991, p. 112), reaffirming the primacy of agency in bringing about cultural change and transformation. On this note, Foster (1986) contends that leadership "must be critically educative; it can not only look at the conditions in which we live, but it must also decide how to change them" (Foster, 1986, p. 185). Likewise, López (2016, p. 26) describes agency as "carving out opportunities within our educational contexts to act in collaboration with others or even sometimes alone. .... Agency is also about building community with others." For Komives and Wagner (2016, p. 399) the change agent is "a person committed to ... lifelong learning, and relationships," and leadership that aims to create change is communal in its nature.

Learning is hence integral to change agency; and critical self-reflection, undertaken individually or collectively, is seen to offer transformative learning opportunities which form part of the journey to becoming a culturally competent leader. A commitment to transformative learning through, for example, communities of practice, is seen to create the conditions needed for learning to learn which is, in turn, a foundational and critical factor in leading for transformation and change. O'Sullivan (2003, p. 328) describes transformative learning as a process that involves:

\footnotetext{
a deep, structural shift in the basic premises of thought, feelings and actions. It is a shift of consciousness that dramatically and irreversibly alters our way of being in the world. Such a shift involves our understanding of ourselves and our self-locations; our relationships with other humans and with the natural world; our understanding of relations of power in interlocking structures of class, race, and gender, our body awareness; ... and our sense of possibilities for social justice, peace, and personal joy.
}

Shields (2010, p. 565) draws on Mezirow's (1991, 1996) transformative learning theory in asserting that "individual learning prompted by self-reflection [is] a tool for deep and lasting personal change." Taylor (2006) and Davis (2006) have since expanded the concept to highlight the need to disrupt and dissect knowledge frameworks and prior learning, as well as acknowledge privileges and power associated with our own culture or other cultures. Cook-Sather and Felten (2017) further this notion by proposing to create spaces for students and educators to interact and learn from each other through an ethic of reciprocity, which "requires a notion of collective responsibility for education - a community rather than only an individualistic approach that deepens the humanity of all involved" (Cook-Sather \& Felten, 2017, p. 182). The authors also draw on Nixon's (2012) concept of the "pedagogized university," which puts mutual respect and reciprocity at the heart of the student-teacher interaction and commits to exploring emergent ideas and differences in perspectives and questioning what is known. Cook-Sather and Felten (2017) support earlier calls (Barr \& Tagg, 1995) for a shift from the instructional paradigm to the learning paradigm in higher education, noting the goal is "not to transfer knowledge but to create environments and experiences that bring students to discover and construct knowledge for themselves" (Cook-Sather \& Felten, 2017, p. 4). 
Communities of practice can be seen as fora for transformative learning and as conducive to both organisational and individual change and transformation. Ewen (2011) draws on Wenger's (2000) six elements seen to be integral to the evolution of an organisational learning strategy, and hence to a community of practice: events, leadership, connectivity, membership, projects and artefacts. Ewen (2011, p. 152) contends that, "cultural competence community of practice can have influence at multiple levels within an organisation ... [as] ... Its activities can have influence across both the actions and consequences, but it can also influence governing value and variables."

The mutual and reciprocal learning, enabled by and through communities of practice, creates opportunities to engage in group critical reflexive practice and can aid in creating a culture of trust and connection, which is fundamental to enlist allies in the drive for change and transformation. On this note, Chun and Evans (2016, p. 70) argue that transformational change "requires that a critical mass of individuals within the institution operate in new ways leading to the establishment of infrastructures that support learning and new norms and habits. Such large-scale changes in practice can be initiated by a small number of individuals." Guerra and Pazey (2016, p. 1754) also highlight the need to establish a strong foundation of trust and openness that would promote a "willingness to think and learn collectively and provide sufficient time for deep and in-depth conversations as vital components to the transformative learning process." Similarly, Cambron-McCabe (2003) advocates for meaningful conversations and behaviours that lead to "learning to learn" together, noting the pivotal role that deep, extended conversation plays in successful transformation and change initiatives at the organisational level. Eckel and Kezar (2003) and Kezar (2005) underscore the important role of leaders in facilitating the necessary structures and process through which higher education institution community members engage in learning.

Finally, leading for change and transformation also requires building partnerships and connecting with local communities. Cooper et al. (2011, p. 4), for example, promote action research by engaging communities as co-partners in education; this is seen as "critical for acknowledging, understanding, and accepting diverse ways of seeing, knowing, and doing." Dantley and Green (2015, p. 833) also contend that:

leadership preparation programs should become accountable to the ... local community in which the university is located ... departments should have a pulse on the educational, social, economic and political conditions of the schools and community in which their universities are located.

Given that cultural competence is relational, effective community engagement, relationship building and collaboration, and person-centred practice (Leotta, 2013) become defining features of cultural competence practice. The need for community engagement in the production of knowledge and scholarship has also been underscored by Kajner (2016, p. 175), who views a reconceptualisation of scholarship (i.e., of community-engaged scholarship) as paramount for universities in regaining relevancy and legitimacy. In the same vein, Wimmer (2016) reinforces the importance of leveraging community knowledge, in his case, Indigenous community knowledge for 
scholarship, noting that knowledge from the community is as valuable and of consequence as that contained in the academy. He highlights the need for the academy to reflect on and query the relevance, reciprocity, respect and responsibility of its interactions and relationships with Indigenous communities, sharing a cautionary position with scholars in the Australian academy, as we will explore in this chapter.

\section{Cultural Competence in the Australian Academy: Setting the Context}

We have thus far reviewed and discussed the literature and scholarship on culturally competent leadership from several comparator countries, namely New Zealand, USA and Canada. Although Australian scholarship on culturally competent leadership in higher education is not prolific, compared to the USA, Canada or New Zealand, scholarly research and debate on cultural competence strategies, methodologies and approaches in higher education abound. Past and existing examples of institutional, organisational and pedagogical approaches to developing culturally competent attributes, skills, behaviours and policies in Australia can be viewed as leadership initiatives in their own right, although they have not necessarily been termed as such. It is also evident that the salient discourses and theories emerging from the literature reviewed thus far are reflected in scholarship emerging from Australia. At the same time, distinctive Australian voices are contributing to this body of scholarship, reflecting the kind of historicity and situational specificity to which Su and Wood (2017) refer. Given the distinct and discrete histories that have impacted contemporary racial, ethnic, cultural and social relations across the USA, Canada, New Zealand and Australia - and their legacies that continue to play out in higher education contexts-experiences differ widely, as do the strategies, methodologies and initiatives aimed at developing cultural competence at the dynamic and holistic levels, explored previously in this chapter.

In Australia, several frameworks that have been developed in the public domain, which address cultural competence/capabilities, have lessons for the academy. The Aboriginal and Torres Strait Islander Cultural Capability Framework (CoA, 2015), for example, highlights three domains of cultural capability: knowing, doing and being. Knowing is about "knowing and understanding history, culture, customs and beliefs"; doing is "culturally appropriate action and behaviour"; and being is about "awareness, authenticity and openness to examining one's own values and beliefs." To develop cultural capabilities requires "continuous development and practice in all three domains, a continuous process of learning" (CoA, 2015, p. 3). The framework views leadership within the context of cultural capability as "a practice rather than a position ... [that] ... can be practised at all levels ... [and is] ... important in setting direction and embedding culture." 
The National Best Practice Framework for Indigenous Cultural Competency in Australian Universities (UA, 2011a, b) has been instrumental in providing guidance and direction on best practice strategies, approaches and methodologies for embedding cultural competence across higher education institutions. UA sees the role of universities as agents of change and committed to leading for transformation and cultural change. In Australia, cultural competence in higher education cannot be separated from social justice, human rights, equity, equal opportunity and reconciliation discourse as it relates to Australia's First Nations peoples and, hence, to Aboriginal and Torres Strait Islander students and staff alike. UA (2011b, p. 3) defines Indigenous cultural competence as follows.

\begin{abstract}
Student and staff knowledge and understanding of Indigenous Australian cultures, histories and contemporary realities and awareness of Indigenous protocols, combined with the proficiency to engage and work effectively in Indigenous contexts congruent to the expectations of Indigenous Australian peoples ... [and] the ability to critically reflect on one's own culture and professional paradigms in order to understand its cultural limitations and effect positive change.
\end{abstract}

Furthermore, Indigenous cultural competence requires "effective and inclusive policies and procedures, monitoring mechanisms and allocation of sufficient resources to foster culturally competent behaviour and practice at all levels of the institution" (UA, 2011b, p. 48). Miralles and Migliorino's (2005) work has served to inform Universities Australia's (UA) directives for embedding cultural competence at the institutional level, which require interventions in all the moving parts that comprise an institution, notably:

- systemic-requiring effective policies and procedures, monitoring mechanisms and sufficient resources to foster culturally competent behaviour and practice at all levels,

- organisational-requiring skills and resources to meet client diversity; an organisational culture which values, supports and evaluates cultural competence as integral to core business,

- Professional—depends on education and professional development, and requires cultural competence standards to guide the working lives of individuals, and

- Individual-requiring the maximisation of knowledge, attitudes and behaviours within an organisation that supports individuals to work with diverse colleagues and customers.

Leadership in all of the domains (institutional, organisational, professional and individual) is seen as fundamental to bringing about the cultural change being called for. There is undoubtedly no blueprint for how this should be done; nor, as the Australian landscape demonstrates, is it a case for a "one size fits all" approach. Su and Wood's (2017) notions of historicity and situational specificity certainly ring true in the Australian higher education context in that, as we will see in this chapter, variables such as organisational culture, institutional history and local (historical, social, political) realities determine the nature, scope and trajectory of strategies and approaches for creating cultural change. 


\section{Home-Grown Cultural Competence Journeys: Theory and Practice from the Field}

There certainly exists rigorous scholarly debate in Australia around what makes for effective Indigenous cultural competence methodologies in the academy. As we have seen from UA's directives, methodologies can vary from Indigenising the curriculum and embedding Indigenous Knowledges (IKs) in course content; to creating safe spaces and enhancing partnerships with local Indigenous communities to inform research methodologies and desired research outputs, and make research of relevance, consequence and benefit to the communities which it claims to serve. The myriad of practices being employed are indicative of innovation, as much as the need for local responses to local needs and circumstances. Echoing the calls of the Aboriginal and Torres Strait Islander Cultural Capability Framework (CoA, 2015) to embrace Indigenous ways of knowing, being and doing, and UA's (2011b) call for IKs in the academy, a number of scholars and practitioners are advocating for greater presence of IKs in higher education. However, there exist divergences on how this approach could be best implemented, which is explored later in this chapter.

There appears to be general agreement that there is a powerful transformative element to pedagogy that is inclusive of diverse ways of knowing, being and doing. Acton, Salter, Lenoy, \& Stevenson (2017, p. 7), for example, discuss the notion of transformative pedagogy at length and highlight the importance of a three-tiered approach that would enable deep and meaningful transformation:

- Situated: valuing localised and nuanced understandings of IKs gained through Aboriginal community consultation, which in turn informs educational content and delivery of content,

- Plural: inclusive of ontological and epistemological plurality, and making space for dominant and diverse ways of knowing, as well as ensuring the "cultural interface" (see Nakata, 2007) between them can be negotiated and challenged, and

- Critical reflexivity: a willingness and ability to engage in the process of selfconfrontation: self-assessment of one's cultural heritage and dominant discourse that has constructed our worldview.

Calma's assertion that "tertiary education institutions exercise cultural leadership when they offer courses that are enriched by Indigenous Knowledges and perspectives" (Calma, 2006) encapsulates some of the key preconditions to leading in a culturally competent way in the Australian higher education sector. These include embedding Indigenous epistemological, ontological and axiological perspectives and standpoints in existing curricula as part of broader social justice, equity and access, and human rights agendas. The "Bradley Review" (Bradley, Noonan, Nugent, \& Scales, 2008) was instrumental in underscoring the value of IKs in the academy, as well as the need for a particular Indigenous graduate attribute (Frawley, 2017). The "Behrendt Review" (Behrendt, Larkin, Griew, \& Kelly, 2012, p. 65) reiterated the Bradley Review's calls, noting that "Indigenous Knowledge, translated into 
practical curriculum, teaching practices, and graduate attributes, makes important contributions to helping professionals meet the needs of Indigenous communities."

In articulating the case for embedding Indigenous ways of knowing, being and doing in the academy as a fundamental step towards cultural change, scholars such as Sherwood \& Russell-Mundine (2017, p. 136) argue that "Western knowledge systems [have] dictated what is considered to be worth knowing within their institutions and silenced the voices and knowledge of those they have managed to construct as the other." Battiste (2002, p. 5) similarly contends that "Indigenous knowledge fills the ethical and knowledge gaps in Eurocentric education, research, and scholarship." Sherwood (2010, p. 124) further argues that "reclaiming Indigenous knowledge systems is paramount to our healing and wellbeing and offers the essence of who we are as peoples."

Martin, Nakata, Nakata, \& Day (2017, p. 1165) consider existing "sociological approaches" to pedagogy in educational contexts, underscoring the diversity of theory, practice and praxis within the Australian educational landscape, as well as the contested nature of these approaches. The authors make specific reference to "two way" or "both ways" learning, of which interculturalism (see Frawley et al. 2010, 2012) is an example, and which is concerned with the intersection and linking of cultural "worlds"; the "space" in which the overlap occurs; and the knowledge that informs this space. Frawley et al. (2010) note that the development of an intercultural identity requires leaders in both cultures to acknowledge the skills, language, knowledge, concepts and understanding from both Aboriginal and non-Aboriginal knowledge systems, whereas interculturalism focuses attention on reciprocity and mutual obligation in the areas of curriculum, knowledge, policies and power.

Citing May and Sleeter's (2010) work, Martin et al. (2017) note that multicultural education has informed the development of different pedagogical approaches in Australia, with strong parallels to critical pedagogy, which in itself includes theoretical orientations such as Indigenous standpoint theory, feminist theory, Marxism and CRT. Decolonising pedagogies are also singled out by Martin et al. (2017) who note that as an emergent and growing agenda, decolonial education secures the incorporation of IKs and practices in the higher education curriculum. Moreover, Grote (2010, p. 248) notes that scholars promote the use of CRT to "undergird teaching and learning in order to challenge students' dominant epistemological and ontological beliefs about themselves, and the world they share with Aboriginal peoples." Nakata, Nakata, Keech, and Bolt (2012, p. 124) further contend that critical theory's "great attraction lies in its promise of overcoming "dominant" power relations and delivering "empowerment" to Indigenous people on the ground in the form of practical action in Indigenous interests."

Decolonisation approaches to education have indeed been advocated for, and implemented by, several Indigenous academics and educational practitioners across Australia. As Nakata et al. (2012) note, the synergies with Latin American decolonising approaches, drawn from the work of Freire (1970), Macedo et al. (1999), Mignolo (2007) and De Lissovoy (2010), are evident in Australian approaches. As another example of decolonising pedagogy, we turn to Sherwood, Keech, Keenan, and Kelly's (2011) account of their students' experiences of the "Introduction to 
Indigenous Cultures: Balancing Worldviews" course. In tracing the decolonisation approach employed and highlighting the centrality of Indigenous relational pedagogy to the course, Sherwood et al. (2011) note:

shifting the space from a dominant colonised space to a space engaging the richness of Indigenous Knowledges, pedagogies, values and protocols was going to prove tricky. Learning in relation to Indigenous ways of knowing encapsulates balance, deep listening and reciprocity. (p. 193)

Moreover, "the task of decolonising education requires multilateral processes of understanding and unpacking the central assumptions of domination, patriarchy, racism, and ethnocentrism that continue to glue the academy's privileges and place" (Battiste et al. 2002, cited in Sherwood et al., 2011, p. 193). The methodology employed in researching and collecting data of student experiences of the course was the Collaborative Community Participatory Action Research method (Sherwood, 2010, 2013; Sherwood, Lighton, Dundas, French, Link-Gordon, Smith, \& Anthony, 2015). This is a "mixed methodological approach inclusive of critical cultural Indigenous protocols" (Sherwood et al., 2011, p. 194) involving storytelling as a data collection approach and focused on reflective and pragmatic action directed to solving problems identified by the collaborative community.

There exist nonetheless gaps in current research on IKs in higher education curricula. Acton et al. (2017) contend that while much of the research in the IKs area has been on research methodologies and epistemologies (Smith, 1999, cited in Acton et al., p. 6), research on Indigenous pedagogies and teaching methodologies is less prolific. The authors assert that adoption of Indigenous pedagogies across Australian university contexts remains inconsistent and understudied, although there are notable efforts and approaches aimed at exploring "the cultural interface of plural ontologies and epistemologies" (Acton et al., 2017, p. 7) such as storytelling, modelling, yarning circles and experiential learning (Acton et al., 2017, p. 10). Sherwood and Russell-Mundine (2017, p. 9) discuss the range of pedagogical models The University of Sydney's National Centre for Cultural Competence (NCCC) employs. These include the Collaborative Community Participatory Action Research method, modelling Indigenous pedagogies with academic peers and embedding these in the NCCC's resources; in addition to developing a specific focus on wellbeing, sense of self and relational learning; growing knowledge about culturally safe spaces; and developing strategies for delivering these spaces throughout the University. In many senses, the NCCC is "developing new ways of working that are not typical of academic environments" (Sherwood \& Russell-Mundine, 2017, p. 9).

\section{Theory and Practice in Australia: Tensions and Contentions}

Our investigation of theory and practice in Australia reveals tensions and contentions in regard to cultural competence best practice in the higher education sector and, for example, the very concept of IKs, which we explore in this section. Notwithstanding these tensions, rigorous scholarly debate has identified gaps and limitations 
in both research and praxis, which bodes well for the future design of strategies, methodologies, and pedagogies aimed at cultural change and transformation.

As previously discussed, embedding IKs in the curriculum is seen to be a fundamental step towards enacting cultural change and transformation. Exactly which IKs to embed and how to embed them are points of contention. Nakata (2004) believes that "the whole area of Indigenous knowledge is a contentious one" (p. 19). "Plonking" Indigenous content into the curriculum, as Nakata describes it (2007, p. 8), will not achieve the fundamental systemic transformation of graduates and institutions that is being called for. Moreover, according to Nakata (2007, p. 9), the manner in which IKs are documented and handled is also problematic in that:

disintegrations and transformations occur when it is redistributed across Western categories of classification, when it is managed in databases via technologies that have been developed in ways that suit the hierarchies, linearity, abstraction and objectification of Western knowledge - all of which are the antithesis of Indigenous knowledge traditions and technologies.

Acton et al. (2017) echo Nakata's (2007) warning that embedding IKs across educational policy, curriculum and pedagogy remains a problematic, complicated, contested and contentious affair that requires more than a simple injection of these knowledges. They underscore the need to be cautious in theorising Indigenous ways of knowing in that localised, and not universalised, articulations need to be accounted for. As the authors note, it is imperative to acknowledge the "diverse and unique knowledge frameworks, values and philosophies of both convergent and divergent groups and peoples that are distinct from Western knowledge systems" (Acton et al., 2017 , p. 5), and that are hence situated, plural and reflexive in their relationality.

Grande (2008) warns of the limitations of critical pedagogic praxis, despite the relevance of critical approaches to both students and educators in need of "pedagogies of disruption, intervention, collectivity, hope and possibility," in that they are "insufficient without an awareness of the tensions and spaces between Western and Indigenous 'thought-worlds"' (Grande, 2008, cited in Acton et al., 2017, p. 11). The issue here is that critical pedagogy, and its emphasis on systematic interrogation, implicitly privileges scientific and rational ways of knowing, being and doing, which are rooted in the western paradigm. To this end, the "root constructs of democratization, subjectivity, and property are all defined through western frames of reference that presume the individual as the primary subjects of 'rights' and social status" (Grande, 2008, cited in Acton et al., 2017, p. 11). However, this is considered problematic and in opposition to Indigenous ways of knowing, being and doing.

An additional and notable object of critique identified in the scholarship relates to the employment of western "quality indicators" to learning and teaching for Indigenous content. Bullen and Flavell (2017, p. 583), for example, argue this demonstrates an "innate lack of institutional understanding of the complexities of teaching interculturally and the 'unlearning' which needs to occur for students to become critically self-reflexive and develop a capacity for ontological pluralism (essential for graduate intercultural capability)." The authors are critical of the entrepreneurial and measured university, which employs a "transactional approach" to embedding IKs into university courses which is deemed as a continuation of epistemic violence on Aboriginal 
and Torres Strait Islander peoples. The transactional approach is underpinned by the "Western model of exchange epitomised by the corporate university: there has been no transformation or decolonisation of knowledges, rather a simplistic exchange that cannot generate new knowledge to transform Indigenous social conditions" (Nakata et al., 2012, p. 121, cited in Bullen \& Flavell, 2017, p. 588). Students themselves are limited in their cultural competence journey by the transactional nature of their studies and as consumers. As the authors note, "the cultural interface needs to be unsettling if transformation is to be achieved. However, challenging students and engaging with concepts such as white privilege does not necessarily result in satisfied customers" (Bullen \& Flavell, 2017, p. 588). The authors ultimately contend that new measures of learning and teaching "quality" must be developed. Additionally, more research is required to understand how students learn Indigenous content, which would result in greater clarity around what indicators could predict the prospect of change and transformation. Ultimately, though, "in a university with meaningful cultural capability, local Elders would determine whether graduates are practice-ready to work with community" (Bullen \& Flavell, 2017, pp. 592-593).

\section{Conclusion}

This review has sought to map and examine the range of designations used in scholarship, mainly from the USA, Canada and New Zealand, that describe leadership in the cultural competence space in higher education settings. We responded to our first two research questions by providing an overview of prominent theory and discourse, bringing to light the binding thread of common attributes, behaviours, knowledge and skills seen to be fundamental to the practice of culturally competent leadership in educational settings. We then shifted our attention to cultural competence in Australian higher education, providing the backdrop needed to address our third and final research question. We set the context by exploring the rationale for cultural change within Australian universities, and the ways in which the higher education sector has heeded the call for embedding cultural competence. We then presented distinctly Australian voices, scholarship and exemplary practice of cultural competence in local higher education contexts, seen to be leadership initiatives in their own right-irrespective of whether these are coined explicitly as "leadership" initiatives. The review then briefly presented points of tension and contention in Australian scholarship around cultural competence initiatives, in an attempt to highlight the burgeoning nature of this field of research and practice in Australian higher education and underscore the contributions of home-grown Australian voices to cultural competence and culturally competent leadership discourse.

The literature consulted for this review has indicated that if the vision of change and transformation is to be realised, the leadership required of the academy and all its constituents is a leadership that is transformative, values-driven, moral, and critically self-reflective and purposeful, in so far as its efforts are geared towards creating a more socially just and equitable university community. This review demonstrates that there 
is no shortage of scholarly debate or academic and professional praxis in Australian higher education drives for cultural competence, and leadership efforts in this space are plentiful, albeit discrete and unique to local settings. There remains room for more research on the impact and outcomes of past and existing initiatives, particularly pedagogical strategies, that could in turn inform future cultural competence models, including leadership professional development programs. There also remains room for more debate around quality measures and, more broadly, around establishing appropriate measurement frameworks that could assess the impact of initiatives in this space. Reconciling concepts of "quality" and "metrics" may prove challenging, particularly when the object of study and measurement is not a single output or product, but the continuous journey of learning that cultural competence represents.

\section{References}

Acton, R., Salter, P., Lenoy, M., \& Stevenson, R. (2017). Conversations on cultural sustainability: Stimuli for embedding indigenous knowledges and ways of being into curriculum. Higher Education Research \& Development, 1-15.

Adserias, R. P., Charleston, L. J., \& Jackson, J. F. (2017). What style of leadership is best suited to direct organizational change to fuel institutional diversity in higher education? Race, Ethnicity and Education, 20(3), 315-331.

Aguirre, A., \& Martinez, R. O. (2002). Leadership practices and diversity in higher education: Transitional and transformational frameworks. Journal of Leadership \& Organizational Studies, $8(3), 53-62$.

Aguirre, A., \& Martinez, R. O. (2006). Diversity leadership in higher education. ASHE-ERIC Higher Education Report, 32(3) (San Francisco, CA: Jossey-Bass).

Barr, R. B., \& Tagg, J. (1995). From teaching to learning-A new paradigm for undergraduate education. Change: The Magazine of Higher Learning, 27(6), 12-26.

Bass, B. M., \& Riggio, R. E. (2006). Transformational leadership. Mahwah, NJ: Lawrence Erlbaum Associates.

Battiste, M. (2002). Indigenous knowledge and pedagogy in First Nations education: A literature review with recommendations. Ottawa, Canada: National Working Group on Education.

Beachum, F. (2011). Culturally relevant leadership for complex 21 st century school contexts. In F. English (Ed.), The SAGE handbook of educational leadership advances in theory, research, and practice. SAGE: Thousand Oaks, CA.

Begley, P. (2001). In pursuit of authentic school leadership practices. International Journal of Leadership in Education, 4(4), 353-365.

Behrendt, L. Y., Larkin, S., Griew, R., \& Kelly, P. (2012). Review of higher education access and outcomes for Aboriginal and Torres Strait Islander people. Final report. Canberra: Department of Industry, Innovation, Science, Research and Tertiary Education.

Bennis, W. (1986). Transformative power and leadership. In T. J. Sergiovanni \& J. E. Corbally (Eds.), Leadership and organizational culture (pp. 64-71). Chicago: University of Illinois Press.

Betancourt, J. R., Green, A. R., Carrillo, J. E., \& Park, E. R. (2005). Cultural competence and health care disparities: Key perspectives and trends. Health Affairs, 24(2), 499-505.

Belich, J. (2009). Replenishing the earth: The settler revolution and the rise of the Anglo-world. Oxford: Oxford University Press.

Bezzina, M., \& Tuana, N. (2014). An insight into the nature of ethical motivation. In C. M. Branson \& S. J. Gross (Eds.), Handbook of ethical educational leadership. New York: Routledge. 
Birnbaum, R. (1992). How academic leadership works: Understanding success and failure in the college presidency. San Francisco: Jossey-Bass Inc.

Bradley, D., Noonan, P., Nugent, H., \& Scales, B. (2008). Review of Australian higher education. Final report. Canberra, Australia: Commonwealth of Australia.

Bullen, J., \& Flavell, H. (2017). Measuring the "gift": Epistemological and ontological differences between the academy and Indigenous Australia. Higher Education Research \& Development, 36(3), 583-596.

Burchum, J. L. R. (2002). Cultural competence: An evolutionary perspective. Nursing Forum, 37(4), $5-15$.

Burns, J. M. (1978). Leadership. New York: Harper and Row.

Calma, T. (2006). What does Australia need to do for cultural competence to flourish? Retrieved from https://www.humanrights.gov.au/about/news/speeches/cultural-competencies-conference.

Cambron-McCabe, N. H. (2003). Rethinking leadership preparation: Focus on faculty learning communities. Leadership and Policy in Schools, 2(4), 285-298.

Chin, J. L., Desormeaux, L., \& Sawyer, K. (2016). Making way for paradigms of diversity leadership. Consulting Psychology Journal: Practice and Research, 68(1), 49.

Chin, J. L., \& Trimble, J. E. (2014). Diversity and leadership. Thousand Oaks, CA: SAGE.

Chun, E., \& Evans, A. (2016). Rethinking cultural competence in higher education: An ecological framework for student development. ASHE Higher Education Report, 42(4), 7-162.

Commonwealth of Australia (CoA). (2015). Aboriginal and Torres Strait Islander cultural capability framework. Retrieved from https://www.apsc.gov.au/aboriginal-and-torres-strait-islandercultural-capability-framework-commonwealth-agencies.

Cook-Sather, A., \& Felten, P. (2017). Ethics of academic leadership: Guiding learning and teaching. Cosmopolitan Perspectives on Academic Leadership in Higher Education, 175.

Cooper, J. E., He, Y., \& Levin, B. B. (2011). Developing critical cultural competence: A guide for 21st-century educators. Corwin Press.

Cruz, N. A. (2015). Privileging Student Voice: Establishing Sustainable Pathways toward Culturally Responsive Leadership in Academe. Culturally Responsive Leadership in Higher Education: Promoting Access, Equity, and Improvement, 226.

d'Arbon, T., Fasoli, L., Frawley, J. \& Ober, R. (2009). Linking worlds: Strengthening the leadership capacity of indigenous educational leaders in remote education settings. Australian Catholic University and Batchelor Institute of Indigenous Tertiary Education.

Damon, W. (2013). Strategic diversity leadership: Activating change and transformation in higher education. Sterling, VA: Stylus Publishing.

Dantley, M. E., \& Green, T. L. (2015). Problematizing notions of leadership for social justice. Journal of School Leadership, 25(5), 820-837.

Day, C. (2000). Effective leadership and reflective practice. Reflective Practice: International and Multidisciplinary Perspectives, 1(1), 113-127.

Davis, S. H. (2006). Influencing transformative learning for leaders. School Administrator, 63(8), 10.

De Lissovoy, N. (2010). Decolonial pedagogy and the ethics of the global. Discourse: Studies in the cultural Politics of Education, 31(3), 279-293.

Eagly, A. H., \& Chin, J. L. (2010). Diversity and leadership in a changing world. American psychologist, 65(3), 216.

Eckel, P. D., \& Kezar, A. J. (2003). Taking the reins: Institutional transformation in higher education. Westport, CT: Greenwood Publishing.

Ewen, S. C. (2011). Cultural competence in medical education: a university case study. (Unpublished doctoral thesis), University of Melbourne, Australia.

Foster, W. (1986). Paradigms and promises. Buffalo, NY: Prometheus.

Frawley, J. (2017). Indigenous Knowledges, graduate attributes and recognition of prior learning for advanced standing: Tensions within the academy. In J. Frawley, S. Larkin, \& J. A. Smith (Eds.), Indigenous pathways, transitions and participation in higher education (pp. 65-80). Springer, Singapore. 
Frawley, J., \& Fasoli, L. (2012). Working together: Intercultural leadership capabilities for bothways education. School Leadership \& Management, 32(4), 309-320.

Frawley, J., Fasoli, L., d'Arbon, T., \& Ober, R. (2010). The linking worlds research project: Identifying intercultural educational leadership capabilities. Leading and Managing, 16(1), 1.

Freire, P. (1970). Pedagogy of the oppressed. New York, NY: Continuum International.

Freire, P. (1998). Pedagogy of freedom: Ethics, democracy, and civic courage. Lanham, MD: Rowman \& Littlefield.

Gooden, M. (2005). The role of an African American principal in an urban information technology high school. Education Administration Quarterly, 41, 630-650.

Gooden, M. (2010). Culturally relevant leadership: How principals can support student learning now. Paper presented at the National Alliance of Black School Educators 38th Annual Conference, Fort Worth, TX.

Grace, A. P. (2016). Socializing higher education for sexual and gender minorities: Using critically progressive education to enhance recognition and accommodation. Assembling and Governing the Higher Education Institution (pp, 385-402). London: Palgrave Macmillan UK.

Grande, S. (2008). Red pedagogy: The un-methodology. In N. Denzin, Y. Lincoln, \& L. Smith (Eds.), Handbook of critical and Indigenous methodologies (pp. 233-254). Thousand Oaks, NY: SAGE.

Grote, E. (2010). Developing an engagement model of cultural competency at the university level: A review of the Literature. National Best Practice Framework for Indigenous Cultural Competency.

Guerra, P. L., \& Pazey, B. L. (2016). Transforming educational leadership preparation: Starting with ourselves. The Qualitative Report, 21(10), 1751-1784.

Halualani, T., \& Nakayama, T. (2010). Critical intercultural communication studies at a crossroads. In T. K Nakayama \& R. T Halualani (Eds.), The handbook of critical intercultural communication (pp. 1-16). Oxford: Wiley-Blackwell.

hooks, b. [sic]. (2010). Teaching critical thinking: Practical wisdom. New York, NY: Routledge.

Horsford, S. D., Grosland, T., \& Gunn, K. M. (2011). Pedagogy of the personal and professional: Toward a framework for culturally relevant leadership. Journal of School Leadership, 21(4), 582-606.

Johnson, L., \& Fuller, C. (2014). Culturally responsive leadership. New York: Oxford University Press.

Jones, S. R., \& McEwen, M. K. (2000). A conceptual model of multiple dimensions of identity. Journal of College Student Development, 41(4), 405.

Kajner, T. (2016). Community-Engaged Scholarship and the Discourse of Academic Privilege in Canadian Higher Education. In Assembling and Governing the Higher Education Institution (pp. 175-196). London: Palgrave Macmillan UK.

Kemmis, S. (2006). Critical theory and participatory action research. In P. Reason \& H. Bradbury (Eds.), SAGE handbook of action research (pp. 121-138). SAGE: Thousand Oaks, CA.

Kezar, A. (2000). Pluralistic leadership. Journal of Higher Education, 71(6), 722.

Kezar, A. J. (2005). What campuses need to know about organizational learning and the learning organization. New Directions for Higher Education, 131, 7-22.

Kezar, A. (2008). Understanding leadership strategies for addressing the politics of diversity. The Journal of Higher Education 79(4):406-441.

Kezar, A. J., Bertram Gallant, T., \& Lester, J. (2011). Everyday people making a difference on college campuses: The tempered grassroots leadership tactics of faculty and staff. Studies in Higher Education, 36(2), 129-151.

Komives, S. R., \& Wagner, W. (Eds.) (2016). Leadership for a better world: Understanding the social change model of leadership development. New York: Wiley.

Leotta, G. (2013). Cultural competency scoping project: Final report. NSW Government: Family $\&$ Community Services. Ageing, Dsability \& Home care.

López, A. E. (2016). Culturally responsive and socially just leadership in diverse contexts: From theory to action. Singapore: Springer. 
Macedo, D., Semali, L., \& Kincheloe, J. (1999). Decolonizing indigenous knowledge. What is indigenous knowledge: Voices from the academy, 134-176.

Mansfield, K. C., \& Jean-Marie, G. (2015). Courageous conversations about race, class, and gender: Voices and lessons from the field. International Journal of Qualitative Studies in Education, 28(7), 819-841.

Marbley, A. F., Bonner, F. A., II, Robinson, P. A., Stevens, H., Li, J., Phelan, K., et al. (2015). Voices from the field of social justice: Defining moments in our professional journeys. Multicultural Education, 23(1), 45.

Martin, G., Nakata, V., Nakata, M., \& Day, A. (2017). Promoting the persistence of Indigenous students through teaching at the Cultural Interface. Studies in Higher Education, 42(7), 11581173.

May, S., \& Sleeter, C. (Eds.). (2010). Critical multiculturalism: Theory and praxis. New York: Routledge.

Mezirow, J. (1991). Transformative dimensions of adult learning. San Francisco, CA: Jossey-Bass.

Mezirow, J. (1996). Contemporary paradigms of learning. Adult Education Quarterly, 46(3), 158 172.

Mignolo, W. D. (2007). DELINKING. Cultural Studies, 21(2-3), 449-514.

Miralles, J., \& Migliorino, P. (2005). Discussion paper: Increasing cultural competency for healthier living. Canberra: National Health and Medical Research Council.

Moses, Y. T. (2014). Diversity, excellence, and inclusion: Leadership for change in the twentyfirst century United States. In D. G. Smith (Ed.), Diversity and inclusion in higher education: Emerging perspectives on institutional transformation. London: Routledge.

Nakata, M. (2004). Indigenous Australian studies and higher education. The Wentworth Lectures, $1-20$.

Nakata, M. (2007). The cultural interface. The Australian Journal of Indigenous Education., 36S, 7-14.

Nakata, M., Nakata, V., Keech, S., \& Bolt, R. (2012). Decolonial goals and pedagogies for Indigenous studies. Decolonization: Indigeneity, Education \& Society, 1(1).

Nixon, J. (2012). Universities as communities of difference. Revista de Pedagogía, 64(3), 15-26.

O'Sullivan, E. (2003). Bringing a perspective of transformative learning to globalized consumption. International Journal of Consumer Studies, 27(4), 326-330.

Ottmann, J. (2009). Leadership for social justice: A Canadian perspective. Journal of Research on Leadership Education, 4(1), 1-9.

Quantz, R. A., Rogers, J., \& Dantley, M. (1991). Rethinking transformative leadership: Toward democratic reform of schools. Journal of Education, 173(3), 96-118.

Ranzijn, R., \& Nolan, W. (2009). Psychology and indigenous Australians: Foundations of cultural competence. South Yarra, VIC: Palgrave Macmillan.

Santamaría, L. J. (2014). Critical change for the greater good: Multicultural perceptions in educational leadership toward social justice and equity. Educational Administration Quarterly, 50(3), 347-391.

Santamaría, L., \& Santamaría, A. (Eds.). (2016). Culturally responsive leadership in higher education: Promoting access, equity, and improvement. New York: Routledge.

Shields, C. M. (2010). Transformative leadership: Working for equity in diverse contexts. Educational Administration Quarterly, 46(4), 558-589.

Sherwood, J. (2010). Do no harm: Decolonising Aboriginal health research (Unpublished doctoral thesis). University of NSW, Sydney.

Sherwood, J. (2013). Collaborative community participation action research (CCPAR): An indigenous research method and methodology. In M. Walter (Ed.), Social research methods (3rd ed.). South Melbourne, VIC: Oxford University Press.

Sherwood, J., Keech, S., Keenan, T., \& Kelly, B. (2011). Indigenous studies: Teaching and learning together. In N. Purdie, G. Milgate, \& H. Rachel Bell (Eds.), Two-way teaching and learning: Toward culturally reflective and relevant education (pp. 189-204). Melbourne: ACER Press. 
Sherwood, J., Lighton, S., Dundas, K., French, T., Link-Gordon, D., Smith, K., \& Anthony, T. (2015). Who are the experts here? AlterNative: An International Journal of Indigenous Peoples, $11(2)$.

Sherwood, J., \& Russell-Mundine, G. (2017). How we do business: Setting the agenda for cultural competence at The University of Sydney. In J. Frawley, S. Larkin, \& J. A. Smith (Eds.), Indigenous pathways, transitions and participation in higher education: From policy to practice. Springer Open: Singapore.

Shultz, L., \& Viczko, M. (2016). Global social justice, democracy and leadership of higher education: An introduction. In J. Laker, L. Shultz, Lynette \& M. Viczko (Eds.), Assembling and governing the higher education institution: Democracy, social justice and leadership in global higher education. London: Palgrave Macmillan.

Smith, L. T. (1999). Decolonizing methodologies: Research and Indigenous peoples. London: Zed Books.

Su, F., \& Wood, M. (Eds.). (2017). Cosmopolitan perspectives on academic leadership in higher education. London: Bloomsbury.

Taylor, E. W. (2006). The challenge of teaching for change. New directions for adult and continuing education, 2006(109), 91-95.

Taylor, K., Durey, A., Mulcock, J., Kickett, M., \& Jones, S. (2015). Developing Aboriginal and Torres Strait Islander cultural capabilities in health graduates: a review of the literature. International Education Journal: Comparative Perspectives, 14(2), 78-89.

Terrell, R. D., \& Lindsey, R. B. (2008). Culturally proficient leadership: The personal journey begins within. Thousand Oaks, CA: Corwin Press.

Thompson, S., Forde, T., \& Otieno, T. (2017). A sustainable, culturally competent approach to academic leadership. In J. L. Chin, J. E. Trimble, E. Joseph, \& J. Garcia (Eds.), Global and culturally diverse leaders and leadership: New dimension and challenges for business, education and society. Bingley, UK: Emerald Publishing.

Tierney, W. G. (1989). Advancing democracy: A critical interpretation of leadership. Peabody Journal of Education, 66(3), 157-175.

Tuleja, E. A. (2014). Developing cultural intelligence for global leadership through mindfulness. Journal of Teaching in International Business, 25(1), 5-24.

Universities Australia. (2011a). Guiding principles for developing Indigenous cultural competency in Australian Universities. Canberra: Universities Australia.

Universities Australia. (2011b). National best practice framework for cultural competency in Australian Universities. Canberra: Universities Australia.

Veracini, L. (2011). Settler colonialism: A theoretical overview. New York: Palgrave Macmillan.

Weiner, E. J. (2003). Secretary Paulo Freire and the democratization of power: Toward a theory of transformative leadership. Educational Philosophy and Theory, 35(1), 89-106.

Wenger, E. (2000). Communities of practice and social learning systems. Organisation, 7(2), 225246.

Wimmer, R. J. (2016). The "4 Rs Revisited," again: Aboriginal education in Canada and implications for leadership in higher education. In J. Laker, L. Shultz, Lynette \& M. Viczko (Eds.), Assembling and governing the higher education institution: Democracy, social justice and leadership in global higher education. London: Palgrave Macmillan.

Zavala, M., \& Tran, N. A. (2016). Negotiating Identities, Locations, and Creating Spaces of Hope for Advancing Students of Color in University Settings. In Culturally Responsive Leadership in Higher Education (pp. 93-105). Routledge.

Alessandra Pecci is currently a lecturer and tutor in International Relations, Communications, and Cultural Studies at Bond University. She was formerly an associate lecturer at the National Centre for Cultural Competence, The University of Sydney. Alessandra is undertaking her $\mathrm{PhD}$ at Bond University. Her doctoral research explores the phenomenon of trans-national and cross-border 
practicing communities of intangible cultural heritage (ICH), and contemplates how UNESCO's definition of ICH 'community' translates to practitioners beyond the homeland of an ICH element.

Jack Frawley has a national and international profile as researcher, writer and educator in the areas of intercultural studies, education, history, leadership studies, and the arts. He has worked extensively as a consultant for program evaluation, research, and education-related projects, in Australian Aboriginal communities as well as in the South Pacific and Southeast Asia, especially in Cambodia.

Tran Nguyen is Associate Lecturer at the National Centre for Cultural Competence, The University of Sydney. She obtained a Master of Philosophy in Development Studies from University of Cambridge, and a Ph.D. in Sociology from Macquarie University. Tran's research interests include international migration, inter-ethnic relations, cultural competence, employment services, and organisational studies.

Open Access This chapter is licensed under the terms of the Creative Commons Attribution 4.0 International License (http://creativecommons.org/licenses/by/4.0/), which permits use, sharing, adaptation, distribution and reproduction in any medium or format, as long as you give appropriate credit to the original author(s) and the source, provide a link to the Creative Commons license and indicate if changes were made.

The images or other third party material in this chapter are included in the chapter's Creative Commons license, unless indicated otherwise in a credit line to the material. If material is not included in the chapter's Creative Commons license and your intended use is not permitted by statutory regulation or exceeds the permitted use, you will need to obtain permission directly from the copyright holder. 